\title{
Induction of a photomixotrophic plant cell culture of Helianthus annuus and optimization of culture conditions for improved $\alpha$ - tocopherol production
}

\footnotetext{
This is the peer-reviewed version from Research Article - Applied Microbiology and Biotechnology, 98, Katja Geipel, Xue Song, Maria Lisa Socher, Sibylle Kümmritz, Joachim Püschel, Thomas Bley, Jutta Ludwig-Müller, Juliane Steingroewer, Induction of a photomixotrophic plant cell culture of Helianthus annuus and optimization of culture conditions for improved alpha-tocopherol production, 2029-2040, 2014, which has been published in final form at: http://dx.doi.org/10.1007/s00253-013-5431-7. (c) 2013 Springer-Verlag Berlin Heidelberg. Personal use of this material is permitted. Permission from publisher must be obtained for all other users. The final publication is available at link.springer.com.
}

$\underline{\text { Katja Geipel }}{ }^{1}$, Xue Song ${ }^{1}$, Maria Lisa Socher ${ }^{1}$, Sibylle Kümmritz ${ }^{1}$, Joachim Püschel ${ }^{2}$, Thomas Bley ${ }^{1}$, Jutta Ludwig-Müller² ${ }^{2}$ Juliane Steingroewer $^{1}$

${ }^{1}$ Institute of Food Technology and Bioprocess Engineering, Technische Universität Dresden, Bergstraße 120, 01069 Dresden, Germany

${ }^{2}$ Institute of Botany, Technische Universität Dresden, Zellescher Weg 20b, 01069 Dresden, Germany

\section{Correspondence}

Katja Geipel, Institute of Food Technology and Bioprocess Engineering, Technische Universität Dresden, Bergstraße 120, 01069 Dresden, Germany

Email: katja.geipel[at]tu-dresden.de

Telephone number: 0049-351-46339042

Fax number: 0049-351-46337761 


\section{Keywords}

sunflower

vitamin $\mathrm{E}$

photosynthesis

photobiotechnology

photomixotrophic

plant in vitro culture 


\section{Abstract}

Tocopherols, collectively known as vitamin E, are lipophilic antioxidants, which are synthesized only by photosynthetic organisms. Due to their enormous potential to protect cells from oxidative damage, tocopherols are used e.g. as nutraceuticals and additives in pharmaceuticals. The most biologically active form of vitamin $\mathrm{E}$ is $\alpha$ tocopherol.

Most tocopherols are currently produced via chemical synthesis. Nevertheless, this always results in a racemic mixture of different and less effective stereoisomers because the natural isomer has the highest biological activity. Therefore, tocopherols synthesized in natural sources are preferred for medical purposes.

The annual sunflower (Helianthus annuus L.) is a well-known source for $\alpha$ tocopherol. Within the presented work, sunflower callus and suspension cultures were established growing under photomixotrophic conditions to enhance $\alpha$-tocopherol yield. The most efficient callus induction was achieved with sunflower stems cultivated on solid Murashige and Skoog medium supplemented with $30 \mathrm{~g} \mathrm{l}^{-1}$ sucrose, $0.5 \mathrm{mg}^{-1}$ of the auxin 1-naphthalene acetic acid and $0.5 \mathrm{mg}^{-1}$ of the cytokinin 6benzylaminopurine. Photomixotrophic sunflower suspension cultures were induced by transferring previously established callus into liquid medium. The effects of light intensity, sugar concentration and culture age on growth rate and $\alpha$-tocopherol synthesis rate were characterized. A considerable increase (max. 230\%) of $\alpha$ tocopherol production in the cells was obtained within the photomixotrophic cell culture compared to a heterotrophic cell culture. These results will be useful for improving $\alpha$-tocopherol yields of plant in vitro cultures. 


\section{Introduction}

Tocopherols are a group of four $(\alpha, \beta, \delta$, and $\gamma)$ lipophilic antioxidants and together with tocotrienols they are commonly known as E vitamers (Franke et al. 2007). In phototrophic organisms, tocopherols are ubiquitous, albeit at different concentrations (Munné-Bosch and Falk 2004). They naturally occur especially in oil seeds, leaves and other parts of higher plants (Kamal-Eldin and Appelqvist 1996). The most biological active component of vitamin E, $\alpha$-tocopherol (Franke et al. 2007) is only synthesized by photosynthetic organisms (Brigelius-Flohé and Traber 1999; Fachechi et al. 2007). The compound itself and most of the enzymes of its biosynthetic pathway are localized in plastid membranes (Lichtenthaler et al. 1981) mainly to protect the photosynthetic apparatus from oxidative damage (Fachechi et al. 2007). Nowadays, tocopherols are applied as additives in foods and pharmaceuticals (Caretto et al. 2010; Ogbonna 2009), because of a recommended daily intake of $\alpha$-tocopherol for adults of $15 \mathrm{mg}$ (Institute of Medicine 2000).

Industrially used $\alpha$-tocopherols are obtained by chemical or biological synthesis. The compounds synthesized chemically consist of a racemic mixture containing also less effective stereoisomers. Those extracted from natural material, known as all-R-form of $\alpha$-tocopherol, possess the highest biological activity (Brigelius-Flohé and Traber 1999). Therefore, tocopherols of biologic origin are preferred. Main sources are plant or vegetable oils such as sunflower, corn and soy bean oil or rape seeds (Britz and Kremer 2002; Franke et al. 2007; Goffman et al. 1999; Velasco et al. 2002). Vegetable oils generally offer a low content of tocopherols compared to a high demand. Thus, an alternative production system of natural tocopherols is strongly desired. 
Besides intact higher plants, plant in vitro cultures are able to produce plant compounds (Smetanska 2008; Georgiev et al. 2009), which was experimentally demonstrated for the first time by Zenk (1991). Subsequently, plant cell cultures have been used for the production of various secondary metabolites, mainly those of high pharmaceutical interest (Bourgaud et al. 2001). With plant in vitro systems a uniform product quality can be ensured. Furthermore, compared to agricultural production, the in vitro production is not influenced by seasonal and environmental conditions Also, no chemical additives against pests and predators will influence the product and its purification (Caretto et al. 2010; Steingroewer et al. 2013).

Recently, researchers try to find alternative sources of $\alpha$-tocopherol using sunflower species (Helianthus sp.). Caretto et al. (2004) tested the increase of $\alpha$-tocopherol levels in different sunflower tissues (hypocotyls, stems, leaves) and in vitro cultures e.g. by the addition of homogentisic acid as a biosynthetic precursor. Gala et al. (2005) reported that the addition of jasmonic acid to the culture medium enhanced the $\alpha$ tocopherol production. Subsequently, Fachechi et al. (2007) successfully increased $\alpha$ tocopherol production by photomixotrophic conditions with decreased sucrose contents in the culture medium. The formation of plastids with photosynthetic activity is increased in photomixotrophic cells compared to heterotrophic conditions. But, in contrast to photoautotrophic metabolism, using photomixotrophic (or photoheterotrophic) metabolism enables the additional utilization of sugar as carbon and energy source (Madigan et al. 2003). Furthermore, in photomixotrophically cultured sunflower cells - compared to cells at heterotrophic conditions - more chloroplasts are localized. In addition, it was noticed an increased expression of the gene for the tocopherol biosynthetic enzyme geranylgeranylpyrophosphate synthase (Fachechi et al. 2007). It is well known that the biosynthesis of $\alpha$-tocopherol in higher 
plants is localized in plastids (Lichtenthaler et al. 1981) and in particular in chloroplasts of photosynthetic tissues (Munné-Bosch and Alegre 2002). Thus, the $\alpha-$ tocopherol production is dependent on light exposure.

Within the presented work, newly generated photomixotrophic callus and suspension cultures of the annual sunflower (H. annuus) were established to enhance $\alpha$ tocopherol yield. The effects of light intensity, sugar concentration, and culture age on growth rates and $\alpha$-tocopherol synthesis have been investigated and compared to a sunflower suspension culture growing under heterotrophic conditions. For the first time, the Respiration Activity MOnitoring System ${ }^{\circledR}$ was used for online monitoring of cell growth of plant in vitro cultures grown under photomixotrophic conditions while applying light via light emitting diodes from the bottoms of the culture vessels. 


\section{Materials and methods}

\section{Callus induction and maintenance}

Seeds of annual sunflower H. annuus L. (HEL 89; Leibniz-Institut für Pflanzengenetik und Kulturpflanzenforschung (IPK), Gatersleben, Germany) were surface sterilized by immersion in $70 \%$ (v/v) ethanol (Carl Roth $\mathrm{GmbH} \& \mathrm{Co} . \mathrm{KG}$, Karlsruhe, Germany) for 2 minutes, followed by immersion in $2 \%(\mathrm{w} / \mathrm{v})$ sodium hypochlorite (Carl Roth) for 10 minutes. After washing twice within sterile distilled water, the seeds were plant in solid Murashige and Skoog (MS) (Murashige and Skoog 1962) medium (micro and macro elements including vitamins), supplemented with $10 \mathrm{~g}^{-1}$ sucrose and $8 \mathrm{~g} \mathrm{l}^{-1}$ phyto agar (Fig. 1a). The germination was executed in plastic containers wherein the seeds were incubated at $26{ }^{\circ} \mathrm{C}$ under continuous fluorescent white light $\left(165 \mu \mathrm{mol} \mathrm{m} \mathrm{m}^{-2} \mathrm{~s}^{-1}, 5 \mathrm{~cm}\right.$ below the light source; Fluora ${ }^{\circledR}$ L 18W/77; Osram GmbH, München, Germany) for approximately 10 days. After in vitro germination, the sterile seedlings (4 $-5 \mathrm{~cm}$ length) were harvested (Fig. $1 \mathrm{~b}$ ) and hypocotyls, stems, cotyledons, and leaves were dissected under sterile conditions and incubated on petri dishes (Fig. 1c) containing three different solid MS medium compositions (MS1, MS2 and MS3) supplemented with $30 \mathrm{~g} \mathrm{l}^{-1}$ sucrose, $7 \mathrm{~g} \mathrm{l}^{-1}$ phyto agar and different plant growth regulators as summarized in Table 1. The explants were incubated at $26^{\circ} \mathrm{C}$ for 2 - 3 weeks in the dark, followed by one week under continuous fluorescent white light, whereby two different light intensities of about 75 and $165 \mu \mathrm{mol} \mathrm{m}^{-2} \mathrm{~s}^{-1}$ (20 and $5 \mathrm{~cm}$ below the light source; Fluora ${ }^{\circledR}$ L 18W/77; Osram) were tested. This light has an emphasis at the blue and red wavelengths of the spectrum and is thereby ideal for promoting photo-biological processes in plants. The measurements of light intensities were carried out using the terrestrial radiation sensor Li-Core ${ }^{\circledR}$ LI-190 Quantum Q 40245 (400 - $700 \mathrm{~nm}$ photosynthetically active 
radiation; LI-COR Biosciences - GmbH, Bad Homburg vor der Höhe, Germany). Light intensity measurements are very sensitive and determined photon current densities difficult to reproduce. Therefore, the distance between cell culture and light source is specified for each intensity used. Nevertheless, deviations of $10-20 \%$ have to be expected.

In order to screen for suitable sucrose content(s), the successfully induced callus cultures (Fig. 1d) were sub-cultured every other week on MS1 (Table 1) with various sucrose concentrations $\left(3 \mathrm{~g} \mathrm{l}^{-1}, 15 \mathrm{~g} \mathrm{l}^{-1}\right.$ and $\left.30 \mathrm{~g} \mathrm{l}^{-1}\right)$ at identical light conditions (165 $\mu \mathrm{mol} \mathrm{m} \mathrm{m}^{-2} \mathrm{~s}^{-1}, 5 \mathrm{~cm}$ below the light source) and $26^{\circ} \mathrm{C}$.

\section{Suspension culture induction, maintenance and cultivation at varying parameters}

Photomixotrophic sunflower suspension cultures were induced by sterile transfer of about $2 \mathrm{~g}$ fresh (biomass) weight (FW in $\mathrm{g}$ ) of callus into liquid MS1 (Table 1) medium under sterile conditions in Erlenmeyer flasks (250 ml nominal volume, $20 \%$ v/v working volume) with wide necks and paper plugs. Cultivation for maintenance was executed on an orbital rotary shaker at $110 \mathrm{rpm}(15 \mathrm{~mm}$ shaking diameter; Sea Star Digital Orbital Shaker; Heathrow Scientific ${ }^{\circledR}$ LLC, Illinois, USA) and $26{ }^{\circ} \mathrm{C}$ under continuous photosynthetically active white light $\left(75 \mu \mathrm{mol} \mathrm{m} \mathrm{m}^{-2} \mathrm{~s}^{-1}, 20 \mathrm{~cm}\right.$ below the light source; Fluora ${ }^{\circledR}$ L 18W/77;). Sub-cultivation was carried out every other week in a ratio of $20 \%$ cell suspension to $80 \%$ fresh MS1 (v/v) supplemented with various concentrations of sucrose $\left(15 \mathrm{~g} \mathrm{l}^{-1}\right.$ and $\left.30 \mathrm{~g}^{-1}\right)$.

A heterotrophic sunflower suspension culture was used for comparison with this photomixotrophic suspension culture. The heterotrophic cells were cultivated in Linsmaier and Skoog (LS) (Linsmaier and Skoog 1965) medium (micro and macro 
elements including vitamins), which was supplemented with $30 \mathrm{~g}^{-1}$ sucrose and $0.2 \mathrm{mg} \mathrm{l}^{-1} 2,4-\mathrm{D}$. The cell suspension was incubated in darkness, but otherwise under the conditions as mentioned above. Sub-cultivation was carried out at weekly intervals in a ratio of $20 \%$ cell suspension to $80 \%$ fresh LS medium (v/v) (Geipel et al. 2013).

For experiments with varying parameters (light intensity, initial sugar content, culture age) a heterotrophic culture grown in darkness $\left(\mathrm{HA}_{h}\right)$, a photomixotrophic induced culture grown in darkness solely for one experiment $\left(\mathrm{HA}_{\mathrm{pm} 30 \mathrm{D}}\right)$ and two photomixotrophic cultures grown under constant light condition with varying initial sucrose contents $\left(15 \mathrm{~g} \mathrm{l}^{-1}\right.$ and $30 \mathrm{~g} \mathrm{l}^{-1} ; \mathrm{HA}_{\mathrm{pm} 30}$ and $\left.\mathrm{HA}_{\mathrm{pm} 15}\right)$ were investigated (Table 2).

Unless otherwise specified, all chemicals and vessels used for induction and cultivation were steam sterilized before usage $\left(121^{\circ} \mathrm{C}, 1\right.$ bar excess pressure, 15 minutes). The $\mathrm{pH}$ of all plant media was adjusted to $5.7 \pm 0.1$ prior sterilization using $10 \% \mathrm{KOH}$. All chemicals and vessels used for induction and cultivation were purchased at Duchefa Biochemie B.V. (Haarlem, The Netherlands) unless otherwise noted.

\section{Suspension culture growth monitoring}

Besides a gravimetric investigation of biomass growth, the Respiration Activity MOnitoring System ${ }^{\circledR}$ RAMOS $^{\circledR}$, HiTec Zang GmbH, Herzogenrath, Germany) was used to determine cell growth. RAMOS enables - via measurement of oxygen partial pressure $\mathrm{p}_{\mathrm{O}_{2}}$ and overall pressure $\mathrm{p}$ (both in bar) - the online detection of the oxygen transfer rate (OTR), the carbon dioxide transfer rate (CTR), and the respiration quotient (RQ) simultaneously in shake flasks under sterile conditions (Anderlei et al. 
2004; Anderlei and Büchs 2001). The RAMOS was set up with eight measuring flasks (250 ml nominal volume) and six standard shake flasks without monitoring unit (Erlenmeyer flasks with narrow necks and, $250 \mathrm{ml}$ nominal volume) cultured under same conditions and used as references (Geipel et al. 2013).

Each flask was inoculated with cell suspensions mixed with fresh medium in a ratio of 20:80 (v/v) to $50 \mathrm{ml}$ initial culture volume. The flasks were orbitally shaken with 110 rpm (25 mm shaking diameter; Lab-Shaker LS-X; Adolf Kühner AG, Birsfelden, Switzerland $)$ at $26{ }^{\circ} \mathrm{C}$, and aerated with ambient air $\left(10 \mathrm{ml} \mathrm{min}^{-1}\right.$ aeration rate; $40 \mathrm{~min}$ measuring phase, 50 min rinsing phase). Illumination of each flask was carried out from beneath the flasks by six light emitting diodes (LED, warm white; PowerBar LED Strip; Nichia Corporation, Tokushima, Japan). Warm white LED provide photons in nearly all wavelength ranges of absorption maxima of the pigments required for photosynthesis, e.g. chlorophylls (430 - $450 \mathrm{~nm}, 640$ - $690 \mathrm{~nm})$. The light intensity is tunable, was measured in advance with the terrestrial radiation sensor mentioned above, and, furthermore, adjusted to $125 \mu \mathrm{mol} \mathrm{m}^{-2} \mathrm{~s}^{-1}$ (mean value out of four measurements inside one empty flask with contact to the LED panel through one $2 \mathrm{~mm}$ acrylic glass for dimming).

For offline analysis standard shake flasks (reference flasks) were removed periodically from the incubator. The cells were separated from the medium via filtration, weighed and freeze dried at $-51^{\circ} \mathrm{C}$ and 0.035 mbar (Alpha 1-2, Martin Christ Gefriertrocknungsanlagen GmbH, Osterode am Harz, Germany). The following offline determination of biomass was conducted using gravimetric methods (Kern 870-13, Kern \& Sohn GmbH, Balingen-Frommern, Germany).

\section{Chlorophyll a and b determination}


Extraction of chlorophyll needs to be carried out in the dark for a definite and consistent sample treatment and recovery. Small sunflower samples $(0.3-0.5 \mathrm{~g} \mathrm{FW})$ were collected before freeze drying of biomass and mixed with $6 \mathrm{ml}$ of acetone:water $(80: 20, \mathrm{v} / \mathrm{v})\left(\mathrm{Carl}\right.$ Roth) at $4{ }^{\circ} \mathrm{C}$ for 60 minutes. Subsequently, the cells were disrupted at $1.5 \mathrm{kbar}$ using a high pressure homogenizer (HAIVA One Shot Head; Constant Systems LTD, Northants, UK). Afterwards, each extract was centrifuged (Biofuge stratos Heraeus, Kendro Laboratory Products GmbH, Osterode, Germany) at $4{ }^{\circ} \mathrm{C}$ and 15,000 $\mathrm{rcf}$ for 10 minutes. The remaining cell pellet was resolved in $5 \mathrm{ml}$ of acetone:water $(80: 20, \mathrm{v} / \mathrm{v})$, extracted and centrifuged again (parameters as mentioned above) to ensure complete extraction. The extraction supernatants were pooled and stored in darkness at $4{ }^{\circ} \mathrm{C}$ till measurements. This method was modified after Corbineau et al. (1988), Liotenberg et al. (1996), Pajević et al. (2004) and Yue et al. (2009).

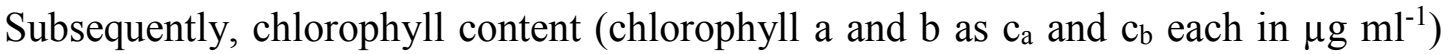
was determined using a spectrophotometer $\left(\mathrm{DU}^{\circledR} 640\right.$ Spectrophotometer, BeckmanCoulter, Brea, USA) and calculated according the equations of Wellburn (1994), whereas $E_{i}$ is the measured extinction at the wavelength of 646 or $663 \mathrm{~nm}$ respectively. The equations 1 and 2 quantify the concentrations of chlorophylls a ( $\left.c_{a}\right)$ and $\mathrm{b}\left(\mathrm{c}_{\mathrm{b}}\right)$ in $\mu \mathrm{g}$ chlorophyll per $\mathrm{ml}$ of acetone:water $(80: 20, \mathrm{v} / \mathrm{v})$ in which the constants are expressed in liter $\mathrm{g}^{-1} \mathrm{~cm}^{-1}$.

$$
\begin{aligned}
& c_{a}=12.21 \cdot E_{663}-2.81 \cdot E_{646} \\
& c_{b}=20.13 \cdot E_{646}-5.03 \cdot E_{663}
\end{aligned}
$$


Finally, results are expressed in mg chlorophyll per g dry (biomass) weight (DW in g) and are calculated as the mean of two technical and one biological replicates.

\section{$\alpha$-Tocopherol determination}

Extraction and GC-MS analysis of $\alpha$-tocopherol were carried out according to Franke et al. (2007) with the following modifications. The weighed dry biomass (about $0.5 \mathrm{~g}$ ) was ground in a mortar after addition of two granules of the hydrophobic antioxidant 3,5-dibutyl-4-hydroxy toluene (Supelco, Sigma-Aldrich, St. Louis, USA). The extraction was performed for 7 minutes with $15 \mathrm{ml}$ pure n-hexane (HPLC grade; Carl Roth). Subsequently, the extract was centrifuged for 8 minutes at 3,980 $\operatorname{rcf}$ (EBA 12, type 1,000; Hettich Zentrifugen, Tuttlingen, Germany). The supernatant was evaporated under constant rotation with $60 \mathrm{rpm}$ at $60{ }^{\circ} \mathrm{C}$ water bath temperature and 150 mbar with a rotary evaporator (rotavapor R-124, waterbath B-480, vacuum distillation controller B-168, all Büchi, Flawil, Switzerland). Subsequently, the residue was resolved in $2 \times 0.5 \mathrm{ml}$ pure $\mathrm{n}$-hexane thoroughly and centrifuged for 5 minutes at 13,000 rpm (Centrifuge 5417R, Eppendorf AG, Hamburg, Germany). The supernatant was transferred into a $1 \mathrm{ml}$ glass vial and supplemented with $\delta$ tocopherol (40 $\mu \mathrm{g} \mathrm{ml}^{-1}$ final concentration, solved in $\mathrm{n}$-hexane) as internal standard. The sample was concentrated by complete vaporization of solvent using a vacuum manifold (Macherey-Nagel GmbH \& Co. KG, Düren, Germany) with constant nitrogen flow rate (about $0.081 \mathrm{~min}^{-1}$ ). After being resolved in $80 \mu 1$ pyridine (SigmaAldrich) the sample was derivatized with $80 \mu \mathrm{l}$ N-Methyl-N(trimethylsilyl)trifluoroacetamide (Macherey-Nagel) in a thermomixer (comfort thermomixer, Eppendorf) at $60{ }^{\circ} \mathrm{C}$ and $300 \mathrm{rpm}$ for 45 minutes and, subsequently, 
dried under constant nitrogen flow again. Finally, the residue was resuspended in $50 \mu 1$ ethyl acetate (Merck KGaA, Darmstadt, Germany) and analyzed by GC-MS.

All chromatographic runs for tocopherol determination were performed on an HP Agilent 7890A GC equipped with HP 7683 B autosampler and split injector interfaced with an HP 5975C MSD inert mass spectrometer (Agilent Technologies, Santa Clara, USA). The gas chromatograph was equipped with an HP-5 MS capillary column (30 m x $0.25 \mathrm{~mm}$ inner diameter coated with a $0.25 \mu \mathrm{m}$ film of cross-linked $5 \%$ phenyl-methyl silicone) and helium was used as carrier gas at $1 \mathrm{ml} \mathrm{min}^{-1}$ flow rate. Aliquots of $1 \mu 1$ sample were automatically injected into the column with a split ratio of 1:20. The temperature program was as follows: $150{ }^{\circ} \mathrm{C}$ for 2 minutes, followed by a heating rate of $25^{\circ} \mathrm{C} \mathrm{min}^{-1}$ to $300{ }^{\circ} \mathrm{C}$ and afterwards 10 minutes at $200{ }^{\circ} \mathrm{C}$. Injector temperature was kept at $250{ }^{\circ} \mathrm{C}$, mass spectrometer source temperature at $230^{\circ} \mathrm{C}$, and quadrupole temperature at $150^{\circ} \mathrm{C}$. The MS was operated in scan mode for providing an overview of components in the sample and in selective ion monitoring mode for quantification of $\alpha$-tocopherol in the samples. The computer software GC/MSD ChemStation (E.02.00.493 Enhanced Data Analysis, Agilent Technologies) was used for peak integration.

Each measurement run was carried out with $\alpha$-tocopherol external standards in 4 different concentrations between $1-200 \mu \mathrm{g} \mathrm{ml}^{-1}$ (standard curve for calibration and control) and $\delta$-tocopherol as internal standard supplemented to both standards and samples at $40 \mu \mathrm{g} \mathrm{ml}^{-1}$. Retention times were about 13 minutes for $\alpha$-tocopherol and about 11 minutes for $\delta$-tocopherol. The ions $502.6 \mathrm{~m} / \mathrm{z}$ for (silylated) $\alpha$-tocopherol and $474.6 \mathrm{~m} / \mathrm{z}$ for $\delta$-tocopherol were used for quantification. The $\alpha$-tocopherol concentrations (in $\mu \mathrm{g} \mathrm{ml}^{-1}$ ) were calculated using means of an external standard calibration (peak-area ratio of $\alpha$-tocopherol to $\delta$-tocopherol). The calibration curve for 
$\alpha$-tocopherol was performed in the range of $1-200 \mu \mathrm{g} \mathrm{ml}^{-1}$ of standard concentration. Subsequently, all results are expressed in $\mu \mathrm{g} \alpha$-tocopherol $\mathrm{g}^{-1} \mathrm{DW}$ and correspond to the mean of two determinations out of one sample measured three times each with relative standard deviations below $5 \%$.

\section{Glucose, fructose and sucrose analysis}

For offline determination of carbohydrate content the cell-free filtrate of each sample was used. The sucrose-splitting enzymes, which are naturally released by the cells, in the filtrate were heat-inactivated (water bath, $80^{\circ} \mathrm{C}, 20 \mathrm{~min}$ ) and, subsequently, the filtrate was stored at $-20{ }^{\circ} \mathrm{C}$ until the measurements. To determine sugar concentrations, filtrates were thawed and analyzed enzymatically or by highperformance liquid chromatography (HPLC).

The HPLC system HP Agilent 1050 Series HPLC (Agilent Technologies) with a pump system and a refractive index detector (1047A, Agilent Technologies) adjusted to $45^{\circ} \mathrm{C}$ was used for sugar analysis. Each filtrate of the culture broth $(1 \mathrm{ml})$ was centrifuged twice at 14,500 $\mathrm{rcf}$ for 15 minutes (Mini Spin ${ }^{\circledR}$ plus, Eppendorf). The supernatant was filtrated once through a regenerated cellulose filter with $0.45 \mu \mathrm{m}$ pore width (17 mm diameter, MF17C645BR, A-Z-Analytik-Zubehör GmbH, Langen, Germany). Before analysis a pre-column SecurityGuard cartridge Carbo- $\mathrm{Pb}$ (4 x $3.0 \mathrm{~mm}$; Phenomenex Inc., Torrance, USA) was used. Subsequently, sugars were separated with a Rezex RPM-Monosaccharide $\mathrm{Pb}+2$ (8\%) (Phenomenex) column ( $300 \times 7.8 \mathrm{~mm}, 8 \mu \mathrm{m}$ particle size) adjusted to $85^{\circ} \mathrm{C}$. The protocol was according the application note TN-1054 from Phenomenex (McGinley 2013) with following additional parameters: $20 \mu 1$ injection volume and ultrapure water as eluent with a flow of $0.6 \mathrm{ml} \mathrm{min}{ }^{-1}$. The computer software HPchem (Rev. A.07.01 [682], Agilent 
Technologies) was utilized for peak integration. In addition to each measurement run 10 external standards of glucose, fructose and sucrose were analyzed. Retention times were about 12 minutes for sucrose, 14 minutes for glucose and 17 minutes for fructose. The calibration curve for glucose and fructose was acquired in the range of $0.05-12.5 \mu \mathrm{g} \mathrm{ml}^{-1}$ of standard concentration, and for sucrose in the range of $0.10-$ $25 \mu \mathrm{g} \mathrm{ml}^{-1}$ of standard concentration.

As an alternative to HPLC analysis an enzymatic test kit for D-glucose/D-fructose and sucrose (E1245, R-Biopharm AG, Darmstadt, Germany) was used. The analysis was carried out as described in the instruction with the only difference of using half the volume of both sample and reagent.

All results of the enzymatic sugar analysis represent the mean of three determinations from one sample. HPLC analysis was carried out in single determinations each. One biological replicate was used for all analyses. Subsequently, all results concerning sugar analytics are expressed in $\mathrm{g}$ sugar $1^{-1}$ filtrate of culture broth with relative standard deviations below $5 \%$.

\section{Statistical issues}

Due to slow growing plant cell cultures which lead in turn to less biomaterial for sampling (offline) analyses - like dry biomass, sugar content, chlorophyll and tocopherol determination - have been executed in single determination. Solely the online measurements of respiration activities were performed for three independent and separate shake flasks $(n=3)$. 


\section{Results}

\section{Callus induction and maintenance}

Stems, hypocotyls, cotyledons, and leaves of seedlings of annual sunflower (H. annuus) were used for induction of photomixotrophic callus cultures (Fig. 1a-c). Furthermore, two light intensities $\left(75\right.$ and $\left.165 \mu \mathrm{mol} \mathrm{m}^{-2} \mathrm{~s}^{-1}\right)$ and three variants of solid media (MS1, MS2 and MS3; Table 1) have been tested. The media only differed in composition and content of plant growth regulators. The MS1 was supplemented with $0.5 \mathrm{mg}^{-1} \mathrm{NAA}$ (auxin) and $0.5 \mathrm{mg} \mathrm{l}^{-1}$ 6-BAP (cytokinin). The MS2 contained $0.5 \mathrm{mg}^{-1}$ 6-BAP but a tenth of NAA compared to MS1. In contrast, the MS3 contained $0.04 \mathrm{mg} \mathrm{l}^{-1}$ 2,4-D (auxin) and $0.02 \mathrm{mg} \mathrm{l}^{-1}$ kinetin (cytokinin). Callus induction rate from hypocotyls, cotyledons, and leaves was very low in all media in contrast to that of stems. Solid MS2 and MS3 failed to induce photomixotrophic callus independent from the part of the plant and the light intensity used. However, after a very short-term treatment of only three weeks, the callus induction on MS1 was successful (Fig. 1d). At low light intensity $\left(75 \mu \mathrm{mol} \mathrm{m}^{-2} \mathrm{~s}^{-1}\right)$ less callus (both less fresh weight and less initial biomass on the original material) was induced than at higher light intensity $\left(165 \mu \mathrm{mol} \mathrm{m} \mathrm{m}^{-2} \mathrm{~s}^{-1}\right)$. It can be concluded that the success of induction of photomixotrophic callus depends mainly on the type of explant used (e.g. source of plant organ), media composition (e.g. plant hormone and initial sugar concentration) (Greco et al. 1984; Mustafa et al. 2011; Thulaseedharan and Vaidyanathan 1990) and light exposure.

The successfully induced light green, soft, and friable callus was collected and subcultivated on solid MS1 at $26^{\circ} \mathrm{C}$ and high light intensity of $165 \mu \mathrm{mol} \mathrm{m} \mathrm{m}^{-2} \mathrm{~s}^{-1}$. Light exposure and sugar content in the culture medium are known to affect the photosynthetic potential of plant in vitro cultures (Groß et al. 1993; Nagatome et al. 
2000). Furthermore, it is public that sucrose lowers chlorophyll levels and hence photosynthesis rate (Hüsemann and Barz 1977). In this work, investigations on solid MS1 with a two-fold and a ten-fold reduced sucrose concentration (15 and $3 \mathrm{~g} \mathrm{l}^{-1}$ ) were performed to analyze and enhance photosynthetic potential and, thus, try to improve tocopherol production (Fachechi et al. 2007). The photomixotrophic callus on MS1 with the lowest initial sucrose content $\left(3 \mathrm{~g} \mathrm{l}^{-1}\right.$, Fig. 2a/b) was almost not growing and, therefore, this medium was unsuitable for further experiments. The callus cultures grown on MS1 with higher initial sucrose content expand rather quickly (Fig. 2c/d and e/f). At the beginning (day 0), these callus cultures showed yellow pigmentation. In the process of cultivation at photomixotrophic conditions, all callus cultures became more greenish, presumably as a result of the chlorophyll synthesis. However, the expected correlation between less amount of sucrose and higher green intensity of the callus could not be observed (compare Fig. 2e/f with $2 \mathrm{a} / \mathrm{b})$.

Within the presented work, stems of sunflower seedlings growing on MS1 with 15 and $30 \mathrm{gl}^{-1}$ initial sucrose content, at $26^{\circ} \mathrm{C}$ and under continuous light at $165 \mu \mathrm{mol} \mathrm{m} \mathrm{m}^{-2} \mathrm{~s}^{-1}$ showed the fastest growth and resulted in the most stable callus. Thus, for further experiments, this callus was chosen for cultivation in liquid MS1 with 15 and $30 \mathrm{~g}^{-1}$ sucrose.

\section{Suspension culture induction and maintenance}

The green, friable photomixotrophic callus obtained from solid MS1 with $30 \mathrm{~g} \mathrm{l}^{-1}$ initial sucrose content was separately transferred into liquid MS1 with the same sucrose concentration and cultivated for maintenance and first growth observations under continuous light $\left(75 \mu \mathrm{mol} \mathrm{m} \mathrm{m}^{-2} \mathrm{~s}^{-1}\right)$. In the early stages the cells seemed to be 
evenly and homogeneously spread in the liquid media (Fig. 3a) and the cell suspensions contained separated cells and cell aggregates. The cell aggregates increased in size with cultivation time (Fig. 3b-c), and formation of new aggregates resulting from newly grown cells is probable. This caused a considerable increase of heterogeneity of suspension culture, which is a common problem with cultivation of plant in vitro systems (Endress 1994). Periodic separation (e.g. via filtration) of large from small cell aggregates followed by further cultivation of smaller aggregates (favored isolated, separated cells) could be a possibility to overcome this challenge (Hulst et al. 1989; Mustafa et al. 2011).

\section{Effects of various parameters on growth ratio and on $\alpha$-tocopherol formation Influence of light intensity}

First, the influence of light on growth and $\alpha$-tocopherol synthesis rate was investigated. A heterotrophic suspension culture of $H$. annuus previously characterized by Geipel et al. (2013) was used for comparison. The following figure (Fig. 4) shows the compared growth ratios of different plant suspension cultures. The growth ratio is described as the ratio between the DW measured at regular intervals and the DW of the inoculum. This parameter was introduced for a better comparison of growth behavior of various cultures. Please refer to Materials and methods, Suspension culture induction, maintenance and cultivation at varying parameters and Table 2 for further information on identification codes for cultures used.

In comparison to the $\mathrm{HA}_{\mathrm{h}}$ culture, the two photomixotrophically induced $\mathrm{HA}_{\mathrm{pm}}$ cultures revealed an obviously reduced growth rate. Nevertheless, the $\mathrm{HA}_{\mathrm{pm} 30 \mathrm{D}}$ cell culture indicated nearly four-fold and the $\mathrm{HA}_{\mathrm{pm} 30}$ cell culture showed three-fold increase of their inoculum till the tenth day of cultivation. For comparison, in the 
same term a 27 -fold increase in the DW concentration of the heterotrophic culture was measured. One possible explanation for this differing growth behavior is the use of different basic media LS and MS for heterotrophic and photomixotrophic suspensions. Ions and ion concentrations of both media are identical, but vitamins differ slightly (Linsmaier and Skoog 1965; Murashige and Skoog 1962). The heterotrophic culture grown in LS with reduced vitamin content in comparison to MS basal medium is growing more intense. A vitamin-specific inhibition of the photomixotrophic $\mathrm{HA}_{\mathrm{pm}}$ culture seems - due to very small differences in vitamin contents - difficult to imagine. Moreover, differences in plant hormone compositions have to be taken into account. LS solely contains a small amount of the auxin analog 2,4-D, whereas MS1 is enriched with more than double the amount of the auxin NAA and additionally the same content of the cytokinin 6-BAP. In addition, efficient carbon supply for photo-active cells compared to heterotrophic cells might be possible.

The $\alpha$-tocopherol contents of $\mathrm{HA}_{\mathrm{h}}, \mathrm{HA}_{\mathrm{pm} 30}$ and the $\mathrm{HA}_{\mathrm{pm} 30 \mathrm{D}}$ cell lines are presented in the same chart (Fig. 4, right axis). It is shown, that the $\mathrm{HA}_{\mathrm{pm} 30 \mathrm{D}}$ culture was almost not able to produce $\alpha$-tocopherol. Because of missing phototrophic stimulation, newly formed cells in this culture are not green pigmented and, probably therefore, the $\alpha-$ tocopherol content declined strongly (Caretto et al. 2004; Fachechi et al. 2007). Moreover, the plant cells with their comparatively complex metabolism are neither yet fully adapted to darkness nor to light. On day 18 , only $4 \mu \mathrm{g} \alpha$-tocopherol $\mathrm{g}^{-1} \mathrm{DW}$ were achieved. The $\alpha$-tocopherol contents of the $\mathrm{HA}_{\mathrm{h}}$ and $\mathrm{HA}_{\mathrm{pm} 30}$ cultures are different but each remain almost constant during the cultivation. On average, the $\mathrm{HA}_{\mathrm{h}}$ cells contain $15 \mu \mathrm{g} \alpha$-tocopherol $\mathrm{g}^{-1} \mathrm{DW}$, whereas the $\mathrm{HA}_{\mathrm{pm} 30}$ culture reveal $40 \mu \mathrm{g} \alpha$ tocopherol $\mathrm{g}^{-1} \mathrm{DW}$, mean. Consequently, a considerable increase of $\alpha$-tocopherol 
synthesis in the $\mathrm{HA}_{\mathrm{pm} 30}$ cells was obtained by comparison with the $\mathrm{HA}_{\mathrm{h}}$ cell culture (almost 3-fold). This observation seems due to the reported photoactive stimulation of $\alpha$-tocopherol biosynthetic pathway (Caretto et al. 2010).

Using the RAMOS with its online measuring unit enables further characterization of growth behavior. Fig. 5 shows representative the online data of a photomixotrophic culture grown in MS1 with $15 \mathrm{~g} \mathrm{l}^{-1}$ initial sucrose content $\left(\mathrm{HA}_{\mathrm{pm} 15}\right)$ at $26^{\circ} \mathrm{C}$ and constant light conditions of $125 \mu \mathrm{mol} \mathrm{m}^{-2} \mathrm{~s}^{-1}$. The OTR is the most suitable measurable parameter to quantify the physiological state of aerobic cultures since most metabolic activities depend on oxygen consumption in heterotrophic cultivation. In addition, the oxygen formation increasingly occurs with increasing phototrophic or photomixotrophic metabolism and, therefore superimposing effects should be kept in mind. An OTR maximum of $0.65 \mathrm{mmol}^{-1} \mathrm{~h}^{-1}$ was detected in the HApm15 suspension. For comparison in the $\mathrm{HA}_{\mathrm{h}}$ culture an OTR maximum of $2.2 \mathrm{mmol} \mathrm{l}^{-1} \mathrm{~h}^{-1}$ was observed (Geipel et al. 2013). Thus, the respiratory activity of $\mathrm{HA}_{\mathrm{h}}$ culture is 3.4-fold higher than the respiratory activity of $\mathrm{HA}_{\mathrm{pm} 15}$ culture. The CTR for both cultures was a bit higher but in the same range as the respective OTR, which results in a RQ of about 1.3 to 1.4 .

\section{Effects of sugar content}

The results of this study show no significant effect of initial sucrose concentration on cell growth of all cultures screened ( $\alpha$-tocopherol production was not investigated for this parameter). The growth ratios of the culture $\mathrm{HA}_{\mathrm{pm} 30}$ with $30 \mathrm{~g} \mathrm{l}^{-1}$ initial sucrose and two photomixotrophic cultures grown with $15 \mathrm{~g} \mathrm{l}^{-1}$ initial sucrose concentration 
(HA $\left.\mathrm{H}_{\mathrm{pm} 15}\right)$ under identical light conditions are for the first two weeks in the same range (Fig. 6) of about 4.

As an example for a typical progress of sugar consumption, the results of sugar analysis are presented for a $\mathrm{HA}_{\mathrm{pm} 15}$ suspension (Fig. 7). In the initial culture medium (day 0 ) about $12 \mathrm{~g} \mathrm{l}^{-1}$ sucrose, $2 \mathrm{~g} \mathrm{l}^{-1}$ fructose and $2 \mathrm{~g} \mathrm{l}^{-1}$ glucose were found, which is presumably due to dilution of fresh medium by $20 \%(\mathrm{v} / \mathrm{v})$ inoculum. First, the disaccharide sucrose was split by the cells enzymatically into the monosaccharides fructose and glucose. This process of the continuous extracellular hydrolysis of sucrose was observed in accordance to the literature (Pavlov et al. 2005). On day 7 of cultivation, the sucrose was metabolized completely. In this period, the highest concentrations of fructose $\left(10 \mathrm{~g} \mathrm{l}^{-1}\right)$ and glucose $\left(5 \mathrm{~g} \mathrm{l}^{-1}\right)$ were detected. Glucose is known to be metabolized preferably by cells of plant in vitro cultures (Haas et al. 2008). Thereafter, the other monosaccharide fructose has been intensively consumed by the cells. From day 10 to 15 , the concentrations decreased rapidly which is due to the exponential cell growth in this phase. The HPLC and enzymatic method with test kit showed nearly identical values (Fig. 7), but the HPLC method is preferred because of its easy sample preparation, as well as its fast and automatic measurement system.

\section{Effects of culture age}

The effects of culture age on growth and $\alpha$-tocopherol synthesis rate were investigated with the photomixotrophic suspension culture $\mathrm{HA}_{\mathrm{pm} 15}$, cultivated at $26^{\circ} \mathrm{C}$ and $125 \mu \mathrm{mol} \mathrm{m} \mathrm{m}^{-2} \mathrm{~s}^{-1}$ with MS1 medium supplemented with $15 \mathrm{~g} \mathrm{l}^{-1}$ initial sucrose. Fig. 8 gives a schematic summary of sub-culture cycles and corresponding ages of the culture used. The first experiment with this culture was carried out four weeks after 
induction of the suspension culture ("young" culture $=\mathrm{HA}_{\mathrm{pm} 15 \mathrm{y}}$ ). The dashed line in Fig. 9a represents the results in terms of growth and shows a six-fold increase in DW until day 15 of the cultivation compared to the DW of the inoculum. Subsequently, this culture was sub-cultivated and, after another four weeks, used again for growth rate characterization and tocopherol analysis ("old" culture $=\mathrm{HA}_{\mathrm{pm} 15 \mathrm{o}}$ ). The dotted line in Fig. 9a shows a linear growth with an increase of growth ratio of about threefold until day 12. Consequently, the growth rate of the photomixotrophic $\mathrm{HA}_{\mathrm{pm} 15}$ suspension decreased about two-fold within four weeks in liquid medium under constant light (data not shown), which demonstrates an influence of culture age on growth behavior.

Furthermore, Fig. 9a depicts the effect of culture age on intracellular $\alpha$-tocopherol concentration (right axis). According to literature (Fachechi et al. 2007; Lichtenthaler et al. 1981; Munné-Bosch and Alegre 2002), the $\alpha$-tocopherol content is usually affected by the chlorophyll content, which means that more green pigments can cause more $\alpha$-tocopherol (Caretto et al. 2004). At the beginning, in the eight weeks old $\mathrm{HA}_{\text {pm15o }}$ culture about $80 \mu \mathrm{g} \alpha$-tocopherol $\mathrm{g}^{-1} \mathrm{DW}$ were determined, which is almost three-fold more than in the four weeks old $\mathrm{HA}_{\mathrm{pm} 15 \mathrm{y}}$ culture at the same stage of the cultivation period. Moreover, during the cultivation progress, $\alpha$-tocopherol content in the $\mathrm{HA}_{\mathrm{pm} 150}$ suspension culture remained consistently higher than in the younger suspension culture. The results indicate that the culture age of the photomixotrophic suspension and therefore the total duration of illumination affects tocopherol synthesis significantly. An adaptation of plant cells to light exposure seems to occur with proceeding light period (Fachechi et al. 2007).

The effect of the culture age on intracellular chlorophyll concentration is shown in Fig. 9b. The chlorophyll content in the four weeks old $\mathrm{HA}_{\mathrm{pm} 15 \mathrm{y}}$ culture remained 
fairly constant during the cultivation and did not exceed $0.5 \mathrm{mg}$ chlorophyll $\mathrm{g}^{-1} \mathrm{DW}$. In comparison, an increase in chlorophyll content was observed for the eight week old $\mathrm{HA}_{\text {pm15o }}$ culture. Its content decreased from $2.2 \mathrm{mg}$ to $0.1 \mathrm{mg}$ chlorophyll $\mathrm{g}^{-1} \mathrm{DW}$ within the first 10 days of cultivation. Afterwards the chlorophyll content increased ten-fold until day $18\left(1.0 \mathrm{mg}\right.$ chlorophyll $\left.\mathrm{g}^{-1} \mathrm{DW}\right)$. It can be assumed that energy from sucrose reduction and carbon metabolism was used first for cell division and growth (primary metabolism) followed by formation of chlorophyll - and only later $\alpha$-tocopherol - in the stationary phase of cultivation (secondary metabolism). Therefore, the chlorophyll content decreased with increasing biomass and increased again in the later growth phase again. In case of a prolonged cultivation cycle, a further increase in chlorophyll synthesis rate is to be expected. In general, in the $\mathrm{HA}_{\text {pm15o }}$ culture approximately two-fold more green-pigments (on days 5 and 12) were observed than in the $\mathrm{HA}_{\mathrm{pm} 15 \mathrm{y}}$ culture, although both cultures grew in the same medium and under the same light conditions. 


\section{Discussion}

\section{Callus induction and maintenance}

The annual sunflower (H. annuus) represents a suitable plant species for the establishment of a photomixotrophic plant cell culture, which produces $\alpha$-tocopherol as a valuable additive for pharmaceutical and food industries. Caretto et al. (2010) reported $\alpha$-tocopherol to be present in extracts from sunflower cell cultures, always more than $91 \%$ of the entire tocopherols. Within the presented work, a stable growing photomixotrophic callus culture, isolated from sunflower seedlings, was established. The results indicate high NAA concentration in combination with 6-BAP (MS1), which was chosen according to Greco et al. (1984), as most suitable for callus induction out of stem explants. This conclusion is commonly known but contradicts the observation of Punia and Bohorova (1992) which monitored good callus induction rate with a tenth of the NAA content used in our study (MS2). Furthermore, callus induction rate from hypocotyls, cotyledons, and leaves was very low in contrast to stems. Therefore, callus induced from stems was chosen for further experiments. From the two different light exposures used, the higher one $\left(165 \mu \mathrm{mol} \mathrm{m} \mathrm{m}^{-2} \mathrm{~s}^{-1}\right)$ proved to be best for green callus induction in such a rate that callus growth was adequate for executing further investigations. Caretto et al. (2010) chose hypocotyl of sunflower seedling as starting tissue and induced a photomixotrophic callus culture with MS1, however at reduced light intensity $\left(125 \mu \mathrm{mol} \mathrm{m} \mathrm{m}^{-2} \mathrm{~s}^{-1}\right)$ but the same sucrose concentration of $30 \mathrm{~g} \mathrm{l}^{-1}$. The induced callus was afterwards successfully sub-cultured on solid MS1 with 30 respectively $15 \mathrm{~g}^{-1}$ sucrose content, in contrast to $3 \mathrm{~g} \mathrm{l}^{-1}$. Summing up, the results presented within this work confirm statements from references according to which type of initial plant tissue, induction and maintenance medium (in terms of plant hormone content), light intensity, as well as initial sucrose 
concentration play an important role for successful induction and maintenance of photomixotrophic sunflower callus cultures. The chosen parameters mentioned above enabled a comparative fast callus induction within a few weeks and should be applied for investigations with other plant species. In addition, the induction of an exclusive photoautotrophic sunflower in vitro culture should be considered.

\section{Suspension culture induction, maintenance and cultivation at varying parameters}

Suspension cultures were established for an improvement of $\alpha$-tocopherol synthesis rate and as an intermediate step in scale-up via laboratory to a later industrial scale. In these cultures correlations between growth and chlorophyll synthesis rate were investigated. In comparison to a heterotrophic sunflower suspension culture grown in darkness, the photomixotrophic cells cultivated under light conditions grew more slowly but synthesized more chlorophyll and $\alpha$-tocopherol per gram biomass. To exclude possible influences of different media compositions used for photo-active and heterotrophic cultures resulting in diverse growth rates further investigations with identic media for all heterotrophic, photomixotrophic and, if applicable, photoautotrophic cultures have to be executed.

Within the presented experiments, the highest $\alpha$-tocopherol content $\left(77 \mu \mathrm{g} \mathrm{g}^{-1} \mathrm{DW}\right)$ was obtained for a photomixotrophic suspension culture grown in liquid MS1 supplemented with $15 \mathrm{~g} \mathrm{l}^{-1}$ sucrose at $26^{\circ} \mathrm{C}$ and light intensity of $125 \mu \mathrm{mol} \mathrm{m}^{-2} \mathrm{~s}^{-1}$. Compared to the heterotrophic suspension culture grown in darkness, an increase in the $\alpha$-tocopherol content per gram DW to a maximum of $230 \%$ was achieved. When comparing the $\alpha$-tocopherol values with literature data, they are similar to other 
sunflower (Caretto et al. 2004) as well as safflower (Carthamus tinctorius) (Furuya et al. 1987) in vitro cultures. But literature data moreover show that plant tissues vary enormously in their tocopherol contents (Gala et al. 2005). According to research of Caretto et al. (2004) sunflower hypocotyls produce $11.4 \mu \mathrm{g} \alpha$-tocopherol $\mathrm{g}^{-1} \mathrm{FW}$, stems $7.3 \mu \mathrm{g} \alpha$-tocopherol $\mathrm{g}^{-1} \mathrm{FW}$ and leaves $18.1 \mu \mathrm{g} \alpha$-tocopherol $\mathrm{g}^{-1} \mathrm{FW}$. Assuming a moisture content of about $90 \%$, the resulting concentrations are approximately $110 \mu \mathrm{g}, 70 \mu \mathrm{g}$ and $180 \mu \mathrm{g} \alpha$-tocopherol $\mathrm{g}^{-1} \mathrm{DW}$, respectively. Although plant in vitro cultures are able to produce $\alpha$-tocopherol, the reported contents are lower than in native plant tissues. Production of plant metabolites with plant cell cultures in a bioreactor results in products at constant quality and quantity during the whole year, with minimal space requirement, without addition of pesticides, fungicides or the like, unaffected by biotic or abiotic environmental factors, and hence at lower cost. This advantages should weigh up the present loss in product content. Furthermore, existing differences in productivity between plant in vivo and in vitro cultures can be overcome by targeted bioprocess engineering and additional process optimization. A dependency of photosynthetic potential of plant in vitro cultures on initial sucrose concentration and light exposure is well known (Groß et al. 1993; Nagatome et al. 2000). Moreover, a reduced sucrose concentration will increase chlorophyll synthesis and, therefore, the photosynthesis rate (Hüsemann and Barz 1977); targeted supply of carbon via aeration with $\mathrm{CO}_{2}$ can also lead to considerable improvement of photoactive growth (Dilorio et al. 1992). In future investigations aeration of the cells with carbon dioxide instead of ambient air without sucrose supply at the same time should be executed to promote exclusive photosynthetic metabolism. Thus, the cells are constrained to receive energy and carbon via photosynthesis and, thereby, presumably further improve their photosynthetic activity in an ideal situation, resulting in 
enhanced growth and tocopherol productivity. Subsequently, an improvement of product formation rate by using biosynthetic precursors should be verified. It is known that precursors influence the genes involved in the tocopherol biosynthesis positively (Creelman and Mullet 1997; Sandorf and Holländer-Czytko 2002). In addition, fundamental knowledge about the relation between light intensity and growth as well as tocopherol production rates during exclusive photoautotrophic metabolism of sunflower suspension cultures is necessary to obtain photo-related parameters like points of photo inhibition, photon saturation or photo compensation and therefore to further optimize growth and production. Biomass and $\alpha$-tocopherol production could be enhanced with an optimization of culture conditions (e.g. improvement of light condition/intensity, variation of light spectrum, variation of bioreactor system, optimization of reactor design). Concerning optimization of reaction systems, an increase of product content was for example observed in a heterotrophic suspension culture of $H$. annuus cultured in a stirred tank reactor (Haas et al. 2008) compared to shake flasks used for this study. Subsequently, culture homogeneity (Endress 1994) may enhance growth and production rate.

\section{Suspension culture growth monitoring, online}

In addition of growth ratio and product formation rate, the OTR, CTR and RQ of the suspension cultures were determined. The OTR and CTR of the photomixotrophic $\mathrm{HA}_{\text {pm15 }}$ culture were about 3-fold lower than the OTR and CTR of the heterotrophic $\mathrm{HA}_{\mathrm{h}}$ culture (Geipel et al. 2013); probably superimposing effects occurring due to photomixotrophic metabolism. Under the influence of light exposure oxygen was presumably produced during photosynthesis and consumed at the same time by respiration. Therefore, the respiration transfer rates of the photomixotrophic culture 
were lower than that of the heterotrophic culture. This observation is in line with the findings by Rechmann et al. (2007) of photosynthetically active duckweed (Wolffia australiana) in vitro culture. Therefore, for experiments using the RAMOS with fluorescent lamps with differing spectra and radiating from above, it was reported that, in case of over-compensation of oxygen consumption by oxygen production, the apparent photosynthesis resulted in negative OTR values for the exclusively photoautotrophic duckweed. This behavior was not observed for the investigated photomixotrophic culture, which is due to the prevalent mixture of photoautotrophic and heterotrophic metabolism with higher proportion of respiration activity. Further studies on influence of light quality should be carried out.

\section{Optimization of culture conditions for improved $\alpha$-tocopherol production}

The authors showed a successful and fast induction of photomixotrophic callus and suspension cultures of $H$. annuus; some parameters have been investigated, the most suitable parameters are published. To characterize growth and product synthesis, different methods have been used. As far as is known to the authors, this was the first time the RAMOS was used for experiments with photomixotrophic plant in vitro cultures in shake flasks under lighting conditions executed with LED and from beneath. Future perspectives are focusing on a deep characterization of growth behavior and production rate mainly in dependency of light quality, intensity and duration. Moreover, investigations concerning respiration transfer rates of photomixotrophic cultured cells as well as solely phototrophic plant in vitro cultures are in progress. The lighting device used will be improved for broad cultivation of diverse photo-active cell lines. 


\section{Acknowledgement}

The authors thank Christiane Haas for critical comments and stimulating discussions, Eva-Maria Kneschke for her great technical support during HPLC analysis, and Kristin Halbauer for assistance.

This work was partially supported financially by European Social Funds (ESF) and the Free State of Saxony (project number: 080938406) as well as the Central Innovation Program of the Federal Ministry of Economics and Technology (BMWi) (project number: KF2049811MD3).

\section{Conflict of interest statement}

The authors declare that they have no conflict of interest. 


\section{References}

Anderlei T, Büchs J (2001) Device for sterile online measurement of the oxygen transfer rate in shaking flasks. Biochem Eng J 7:157-162

Anderlei T, Zang W, Papaspyrou M, Büchs J (2004) Online respiration activity measurement (OTR, CTR, RQ) in shake flasks. Biochem Eng J 17:187-194

Bourgaud F, Gravot A, Milesi S, Gontier E (2001) Production of plant secondary metabolites: a historical perspective. Plant Sci 161:839-851

Brigelius-Flohé R, Traber MG (1999) Vitamin E: function and metabolism. FASEB J $13: 1145-1155$

Britz SJ, Kremer DF (2002) Warm temperatures or drought during seed maturation increase free $\alpha$-tocopherol in seeds of soybean (Glycine max [L.] Merr.). J Agr Food Chem 50:6058-6063

Caretto S, Nisi R, Paradiso A, De Gara L (2010) Tocopherol production in plant cell cultures. Mol Nutr Food Res 54:726-730

Caretto S, Speth EB, Fachechi C, Gala R, Zacheo G, Giovinazzo G (2004) Enhancement of vitamin E production in sunflower cell cultures. Plant Cell Rep 23:174-179

Corbineau F, Rudnicki RM, Côme D (1988) The effects of methyl jasmonate on sunflower (Helianthus annuus L.) seed germination and seedling development. Plant Growth Regul 7:157-169

Creelman RA, Mullet JE (1997) Biosynthesis and action of jasmonates in plants. Annu Rev Plant Phys 48:355-381

Dilorio AA, Cheetham RD, Weathers PJ (1992) Carbon dioxide improves the growth of hairy roots cultured on solid medium and in nutrient mists. Appl Microbiol Biot 37:463-467 
Endress R (1994) Plant cell biotechnology. Springer-Verlag, Berlin, New York

Fachechi C, Nisi R, Gala R, Leone A, Caretto S (2007) Tocopherol biosynthesis is enhanced in photomixotrophic sunflower cell cultures. Plant Cell Rep 26:525530

Franke AA, Murphy SP, Lacey R, Custer LJ (2007) Tocopherol and tocotrienol levels of foods consumed in Hawaii. J Agr Food Chem 55:769-778

Furuya T, Yoshikawa T, Kimura T, Kaneko H (1987) Production of tocopherols by cell culture of safflower. Phytochemistry 26:2741-2747

Gala R, Mita G, Caretto S (2005) Improving $\alpha$-tocopherol production in plant cell cultures. J Plant Physiol 162:782-784

Geipel K, Socher ML, Haas C, Bley T, Steingroewer J (2013) Growth kinetics of a Helianthus annuus and a Salvia fruticosa suspension cell line: shake flask cultivations with online monitoring system. Eng Life Sci 13:593-602

Georgiev MI, Weber J, Maciuk A (2009) Bioprocessing of plant cell cultures for mass production of targeted compounds. Appl Microbiol Biot 83:809-823

Goffman FD, Velasco L, Thies W (1999) Quantitative determination of tocopherols in single seeds of rapeseed (Brassica napus L.). Fett-Lipid 101:142-145

Greco B, Tanzarella OA, Carrozzo G, Blanco A (1984) Callus induction and shoot regeneration in sunflower (Helianthus annuus L.). Plant Sci Lett 36:73-77

Groß U, Gilles F, Bender L, Berghöfer P, Neumann K-H (1993) The influence of sucrose and an elevated $\mathrm{CO}_{2}$ concentration on photosynthesis of photoautotrophic peanut (Arachis hypogaea L.) cell cultures. Plant Cell Tiss Org 33:143-150

Haas C, Weber J, Ludwig-Müller J, Deponte S, Bley T, Georgiev M (2008) Flow cytometry and phytochemical analysis of a sunflower cell suspension culture 
in a 5-L bioreactor. Z Naturforsch C 63c:699-705

Hüsemann W, Barz W (1977) Photoautotrophic growth and photosynthesis in cell suspension cultures of Chenopodium rubrum. Physiol Plantarum 40:77-81

Hulst AC, Meyer MMT, Breteler H, Tramper J (1989) Effect of aggregate size in cell cultures of Tagetes patula on thiophene production and cell growth. Appl Microbiol Biot 30:18-25

Institute of Medicine (2000) Dietary reference intakes for vitamin C, vitamin E, selenium and carotenoids. National Academy Press, Washington, DC

Kamal-Eldin A, Appelqvist L-Å (1996) The chemistry and antioxidant properties of tocopherols and tocotrienols. Lipids 31:671-701

Lenk F, Vogel M, Bley T, Steingroewer J (2012) Automatic image recognition to determine morphological development and secondary metabolite accumulation in hairy root networks. Eng Life Sci 12:588-594

Lichtenthaler HK, Prenzel U, Douce R, Joyard J (1981) Localization of prenylquinones in the envelope of spinach chloroplasts. Biochim Biophys Acta 641:99-105

Linsmaier EM, Skoog F (1965) Organic growth factor requirements of tobacco tissue cultures. Physiol Plantarum 18:100-127

Liotenberg S, Campbell D, Rippka R, Houmard J, de Marsac NT (1996) Effect of the nitrogen source on phycobiliprotein synthesis and cell reserves in a chromatically adapting filamentous cyanobacterium. Microbiol 142:611-622

Madigan MT, Martinko JM, Parker J (2003) Brock biology of microorganisms. Pearson Education International, Upper Saddle River, New Jersey

Mc Ginley M (2013) Optimizing the analysis of sugar alcohol excipients in pharmaceutical tablet fomulations using $\operatorname{Rezex}^{\mathrm{TM}}$ ion exclusion HPLC 
columns. Phenomenex applications TN-1054, Torrance, USA

Munné-Bosch S, Alegre L (2002) The function of tocopherols and tocotrienols in plants. Crc Cr Rev Plant Sci 21:31-57

Munné-Bosch S, Falk J (2004) New insights into the function of tocopherols in plants. Planta 218:323-326

Murashige T, Skoog F (1962) A revised medium for rapid growth and bio assays with tobacco tissue cultures. Physiol Plantarum 15:473-497

Mustafa NR, de Winter W, van Iren, F, Verpoorte R (2011) Initiation, growth and cryopreservation of plant cell suspension cultures. Nat Protoc 6:715-742

Nagatome H, Tsutsumi M, Kino-Oka M, Taya M (2000) Development and characterization of a photoautotrophic cell line of pak-bung hairy roots. J Biosci Bioeng 89:151-156

Ogbonna JC (2009) Microbiological production of tocopherols: current state and prospects. Appl Microbiol Biot 84:217-225

Pajević S, Vasić D, Sekulić P (2004) Biochemical characteristics and nutrient content of the callus of sunflower inbred lines. Helia 27:143-150

Pavlov A, Werner S, Ilieva M, Bley T (2005) Characteristics of Helianthus annuus plant cell culture as a producer of immunologically active exopolysaccharides. Eng Life Sci 5:280-283

Punia MS, Bohorova NE (1992) Callus development and plant regeneration from different explants of six wild species of sunflower (Helianthus L.). Plant Sci $87: 79-83$

Rechmann H, Friedrich A, Forouzan D, Barth S, Schnabl H, Biselli M, Boehm R (2007) Characterization of photosynthetically active duckweed (Wolffia australiana) in vitro culture by respiration activity monitoring system 
(RAMOS). Biotechnol Lett 29:971-977

Sandorf I, Holländer-Czytko H (2002) Jasmonate is involved in the induction of tyrosine aminotransferase and tocopherol biosynthesis in Arabidopsis thaliana. Planta 216:173-179

Smetanska I (2008) Production of secondary metabolites using plant cell cultures. Adv Biochem Eng Biot 111:187-228

Steingroewer J, Bley T, Georgiev V, Ivanov I, Lenk F, Marchev A, Pavlov A (2013) Bioprocessing of differentiated plant in vitro systems. Eng Life Sci 13:26-38

Thulaseedharan A, Vaidyanathan CS (1990) Induction of callus and plant regeneration in Vicoa indica. Plant Cell Tiss Org 23:45-48

Velasco L, Fernández-Martínez JM, García-Ruíz R, Domínguez J (2002) Genetic and environmental variation for tocopherol content and composition in sunflower commercial hybrids. J Agr Sci 139:425-429

Wellburn AR (1994) The spectral determination of chlorophylls $a$ and $b$, as well as total carotenoids, using various solvents with spectrophotometers of different resolution. J Plant Physiol 144: 307-313

Yue B, Cai X, Vick B, Hu J (2009) Genetic characterization and molecular mapping of a chlorophyll deficiency gene in sunflower (Helianthus annuus). J Plant Physiol 166:644-651

Zenk MH (1991) 6. Chasing the enzymes of secondary metabolism: plant cell cultures as a pot of gold. Phytochemistry 30:3861-3863 
Table 1 Medium names and correlation to corresponding plant hormone compositions of different MS media used for photomixotrophic sunflower cultures

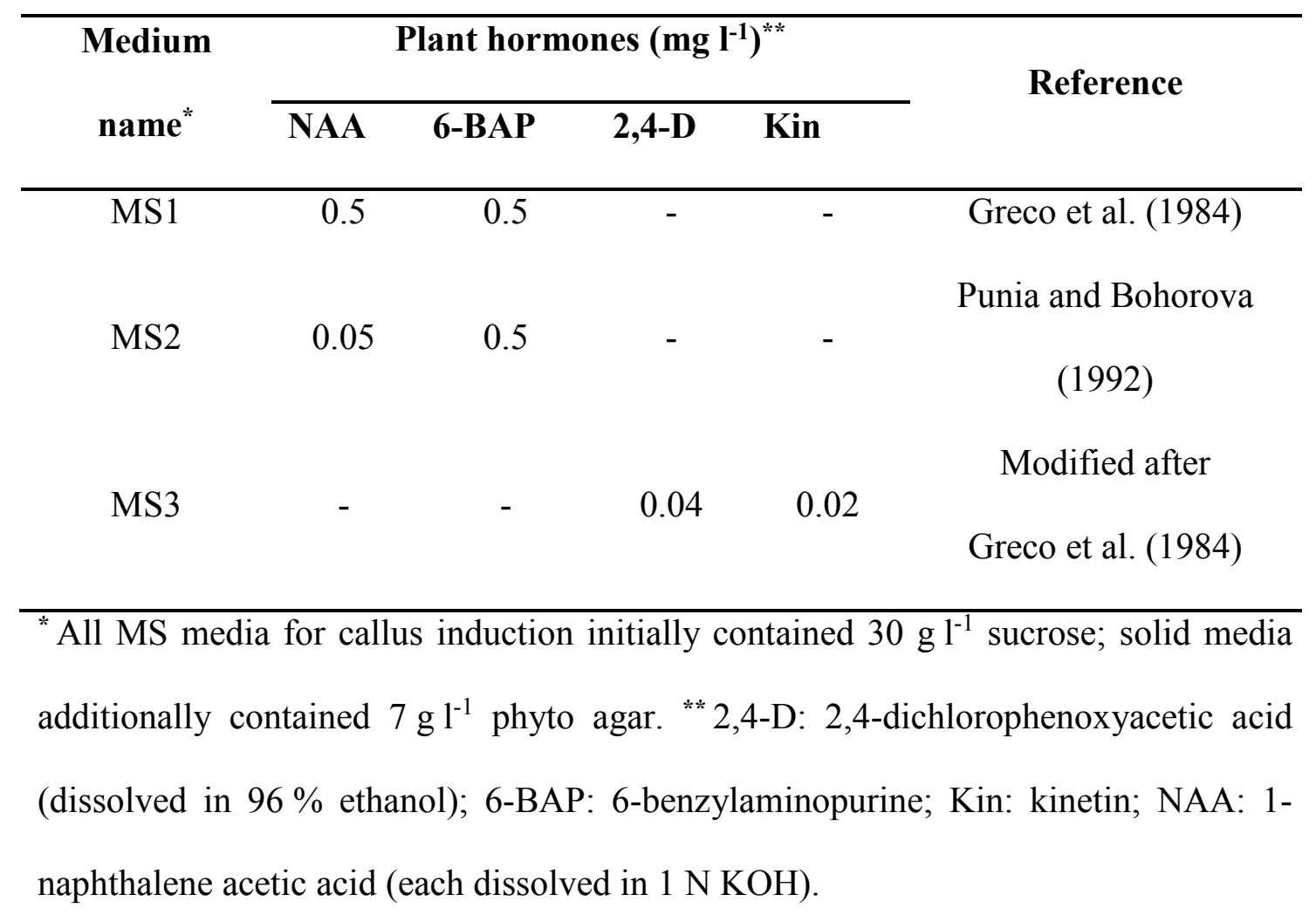

Table 2 Identification codes and correlation to corresponding cultivation conditions of investigated sunflower suspension cultures

\begin{tabular}{|c|c|c|c|c|c|c|}
\hline \multirow{2}{*}{$\begin{array}{c}\text { Identification } \\
\text { codes }\end{array}$} & \multirow{2}{*}{$\begin{array}{c}\text { Basic } \\
\text { medium }\end{array}$} & \multicolumn{3}{|c|}{ Plant hormones $\left(\mathrm{mg} \mathrm{l}^{-1}\right)^{* *}$} & \multirow{2}{*}{$\begin{array}{l}\text { Sucrose } \\
\left(\mathrm{g} \mathrm{l}^{-1}\right)\end{array}$} & \multirow{2}{*}{ 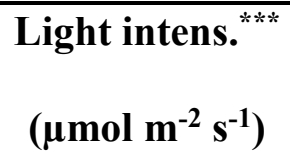 } \\
\hline & & $2,4-D$ & NAA & 6-BAP & & \\
\hline $\mathrm{HA}_{\mathrm{h}}$ & $\mathrm{LS}$ & 0.2 & - & - & 30 & - \\
\hline $\mathrm{HA}_{\mathrm{pm} 30 \mathrm{D}}$ & MS & - & 0.5 & 0.5 & 30 & - \\
\hline $\mathrm{HA}_{\mathrm{pm} 30}$ & MS & - & 0.5 & 0.5 & 30 & 125 \\
\hline $\mathrm{HA}_{\mathrm{pm} 15}$ & MS & - & 0.5 & 0.5 & 15 & 125 \\
\hline \multicolumn{7}{|c|}{${ }^{* *}$ Please refer to Table 1 for abbreviations of plant hormones. ${ }^{* * *}$ Please refer to } \\
\hline Materials and $r$ & thods, $\mathrm{St}$ & ension & ture $g$ & wth mor & ring for & arther information \\
\hline
\end{tabular}




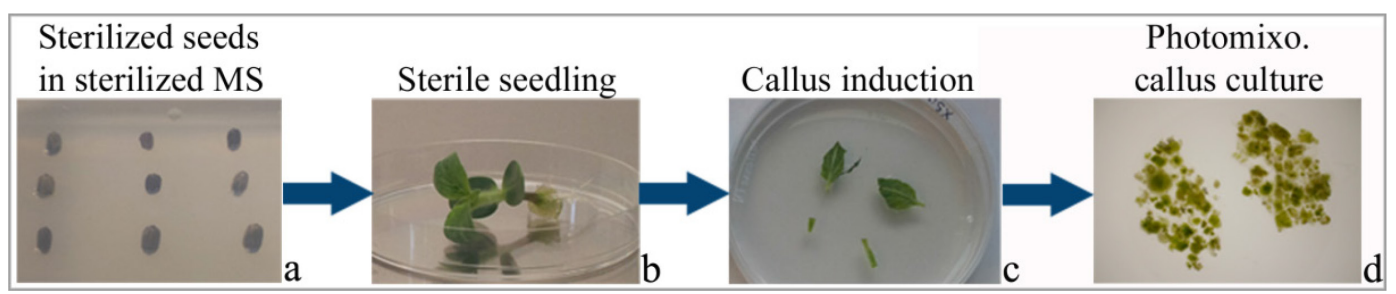

Fig. 1 Scheme of induction of photomixotrophic callus. a Sterilized sunflower seeds in sterilized solid MS. b Sterile sunflower seedling. c Sunflower single organs on sterilized solid MS. d Induced green sunflower callus culture

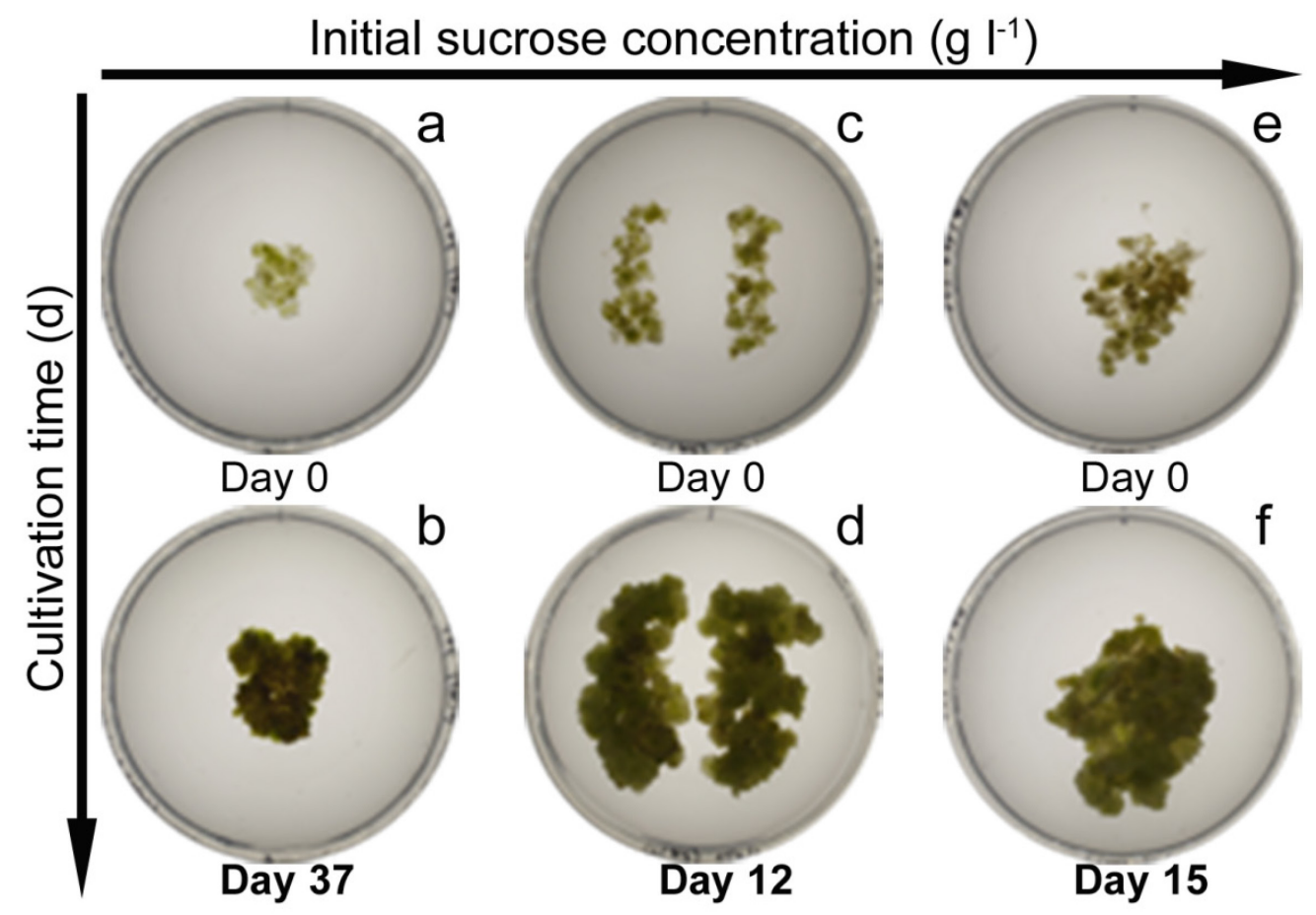

Fig. 2 Callus growth dependent on initial sucrose content (solid MS1 according Table 1; cultivation at $26^{\circ} \mathrm{C}$ and $165 \mu \mathrm{mol} \mathrm{m} \mathrm{m}^{-2}$ ). a/b $3 \mathrm{~g} \mathrm{l}^{-1}$ sucrose. c/d $15 \mathrm{~g} \mathrm{l}^{-1}$ sucrose. e/f $30 \mathrm{~g} \mathrm{l}^{-1}$ sucrose. Image recording with help of the tripod for image acquisition according to Lenk (2012) 


\section{Cultivation time (d)}

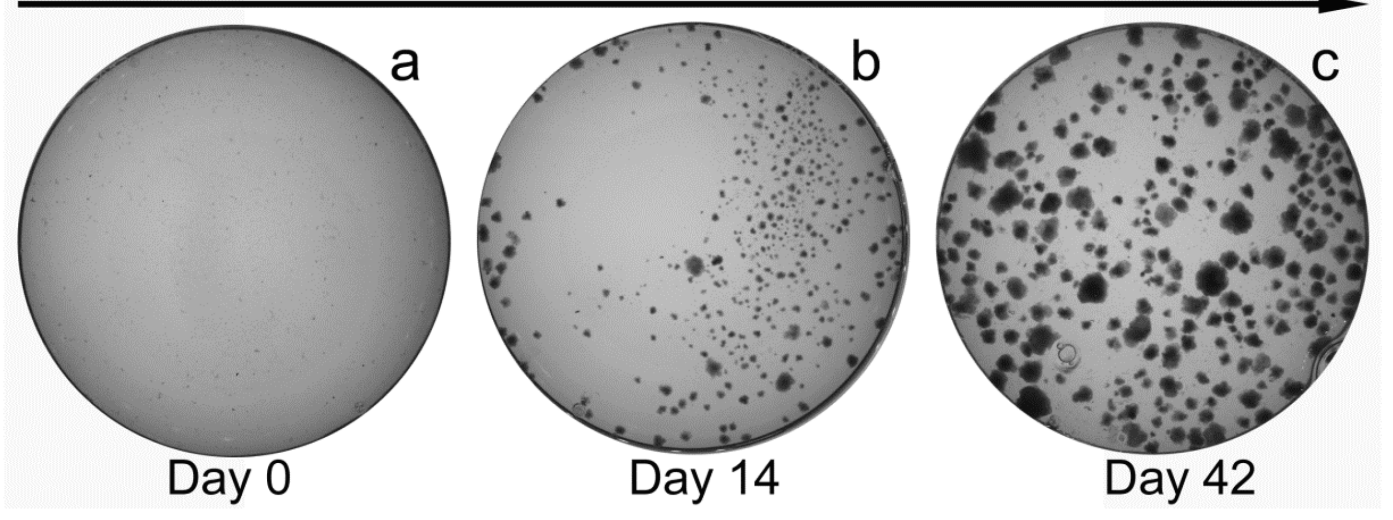

Fig. 3 Increase of size and quantity of cell aggregates in photomixotrophic sunflower suspensions during cultivation. a Recently transferred from callus in suspension culture. b After 2 weeks in liquid medium (end of first sub-culture cycle). c After 6 weeks in liquid medium (end of third sub-culture cycle). Image recording from beneath the shake flasks with help of the tripod for image acquisition according to Lenk (2012)

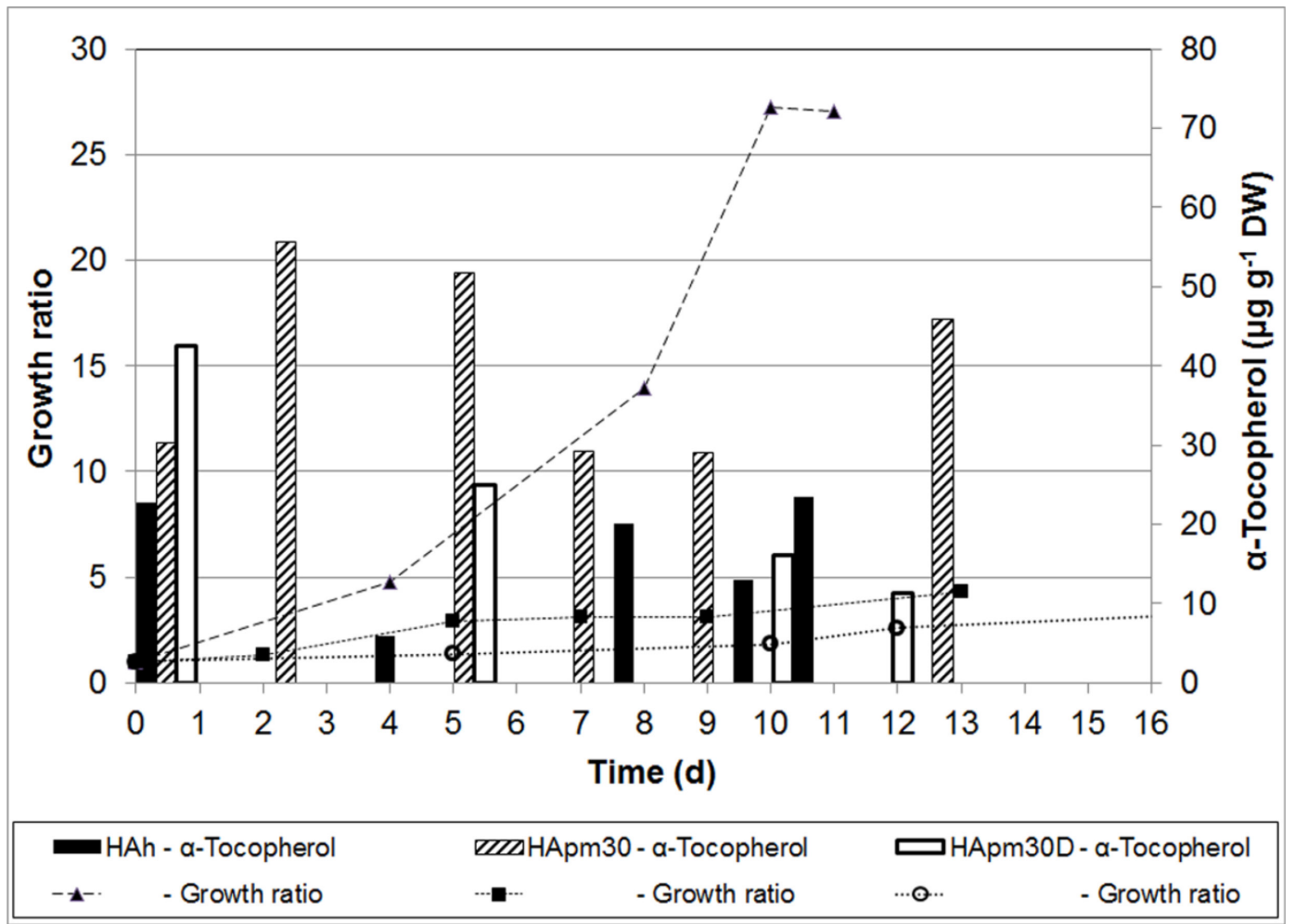


Fig. 4 Effects of light on growth ratio and $\alpha$-tocopherol synthesis of photomixotrophic sunflower suspension cultures grown in MS1 with $30 \mathrm{~g}^{-1}$ initial sucrose content at $26^{\circ} \mathrm{C}$ and $125 \mu \mathrm{mol} \mathrm{m}^{-2} \mathrm{~s}^{-1}$ or in darkness, respectively, and comparison with a heterotrophic sunflower suspension culture grown in LS with $30 \mathrm{gl}^{-1}$ initial sucrose content in darkness $(\mathrm{n}=1)$. Growth ratios of $\mathrm{HA}_{\mathrm{h}}$ ( $\boldsymbol{\Delta}$ long dashed line), $\mathrm{HA}_{\mathrm{pm} 30}\left(\boldsymbol{\square}\right.$ dashed line), and $\mathrm{HA}_{\mathrm{pm} 30 \mathrm{D}}(\mathrm{O}$ dotted line). Intracellular $\alpha-$ tocopherol content in $\mathrm{HA}_{\mathrm{h}}$ (black column), $\mathrm{HA}_{\mathrm{pm} 30}$ (striped column) and $\mathrm{HA}_{\mathrm{pm} 30 \mathrm{D}}$ (white column). Total duration of cultivation: 11 days for $\mathrm{HA}_{\mathrm{h}}, 13$ days for $\mathrm{HA}_{\mathrm{pm} 30}$ and 18 days for $\mathrm{HA}_{\mathrm{pm} 30 \mathrm{D}}$

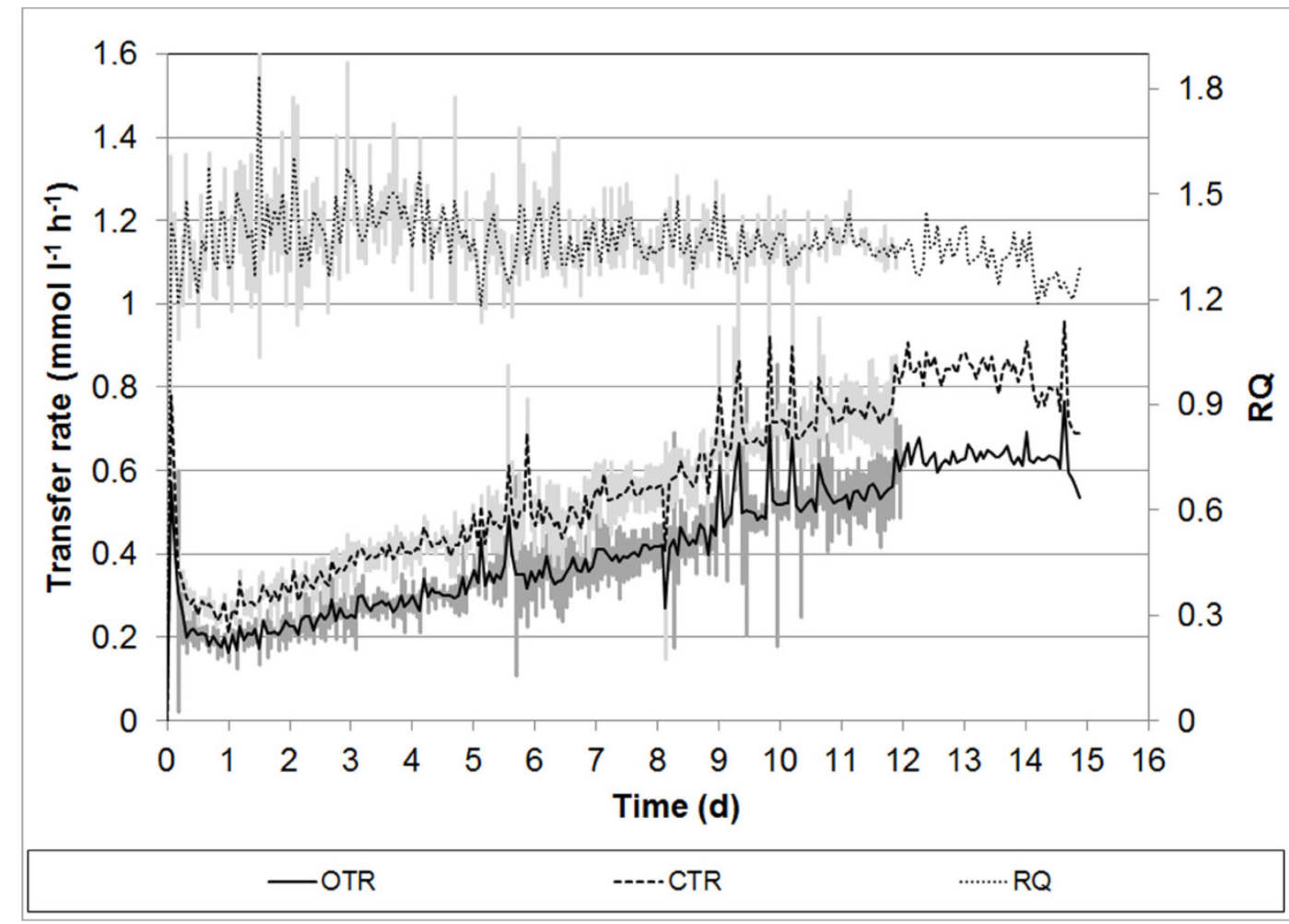

Fig. 5 OTR (solid line), CTR (dashed line) and RQ (dotted line, right axis) (each with standard deviations out of $n=3$ values shown in grey) of a photomixotrophic sunflower suspension culture $\left(\mathrm{HA}_{\mathrm{pm} 15}\right)$. Cultivation conditions: RAMOS, orbital rotary shaker (25 mm shaking diameter), $110 \mathrm{rpm}, 26{ }^{\circ} \mathrm{C}, 125 \mu \mathrm{mol} \mathrm{m}{ }^{-2} \mathrm{~s}^{-1}$, RAMOS 
flasks (250 ml nominal volume), $50 \mathrm{ml}$ filling volume, MS1 with $15 \mathrm{~g} \mathrm{l}^{-1}$ initial sucrose content, $\mathrm{pH}$ 5.7; aeration with ambient air $\left(10 \mathrm{ml} \mathrm{min}^{-1}\right.$ aeration rate; $40 \mathrm{~min}$ measuring phase, 50 min rinsing phase). On day 12 of cultivation measuring flasks were taken as samples which results in a reduced number of determinations. Therefore, no more standard deviations are indicated.

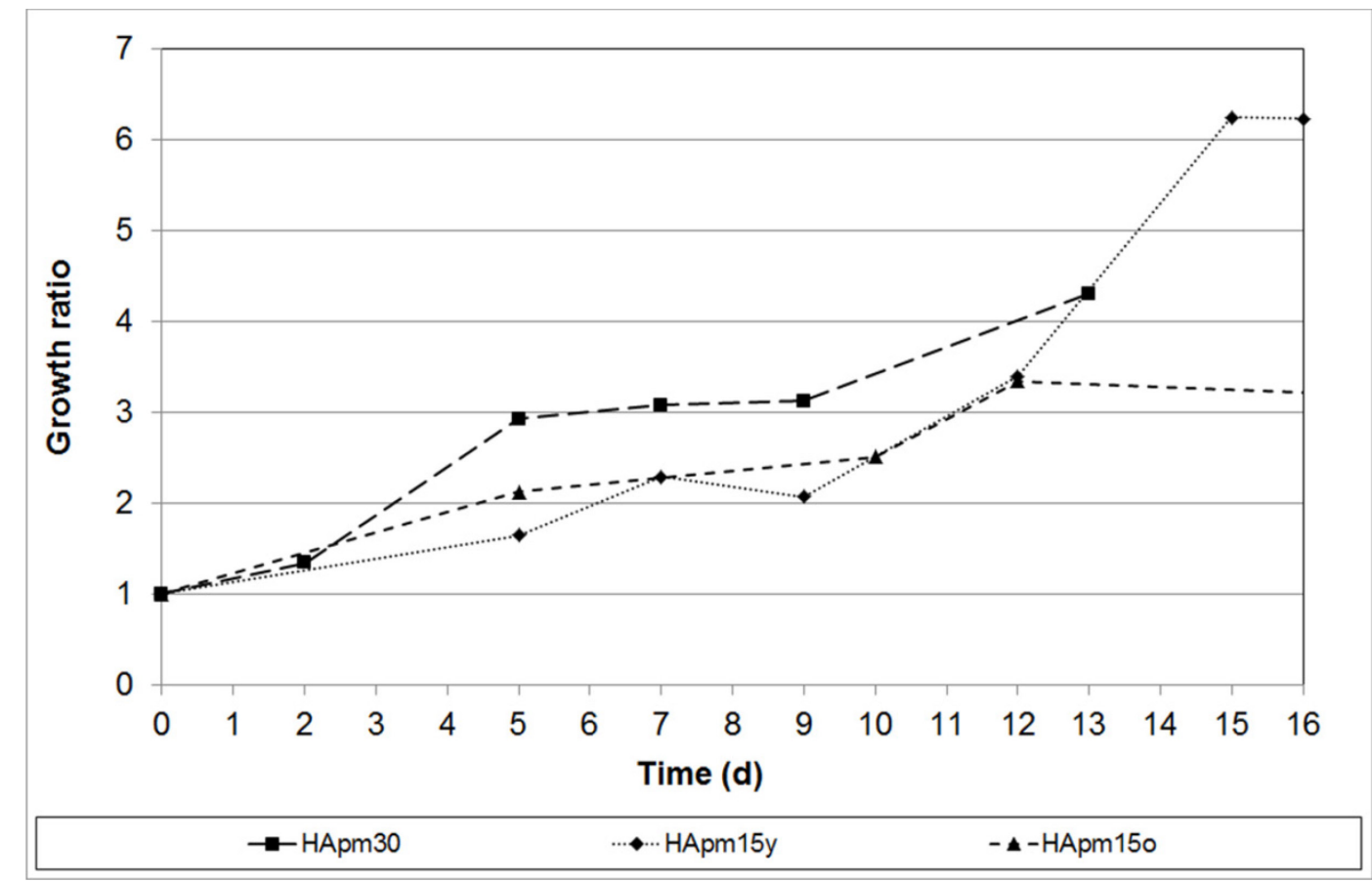

Fig. 6 Effects of sugar content on growth ratio of photomixotrophic sunflower suspension cultures grown in MS1 with 30 and $15 \mathrm{~g} \mathrm{l}^{-1}$ initial sucrose content at $26^{\circ} \mathrm{C}$ and $125 \mu \mathrm{mol} \mathrm{m} \mathrm{m}^{-2} \mathrm{~s}^{-1}(\mathrm{n}=1)$. Growth ratios of $\mathrm{HA}_{\mathrm{pm} 30}$ (घlong dashed line), $\mathrm{HA}_{\mathrm{pm} 15 \mathrm{y}}($ dotted line), and $\mathrm{HA}_{\mathrm{pm} 150}(\boldsymbol{\Delta}$ dashed line). Total duration of cultivation: 13 days for $\mathrm{HA}_{\mathrm{pm} 30}, 16$ days for $\mathrm{HA}_{\mathrm{pm} 15 \mathrm{y}}$ and 18 days for $\mathrm{HA}_{\mathrm{pm} 150}$ 


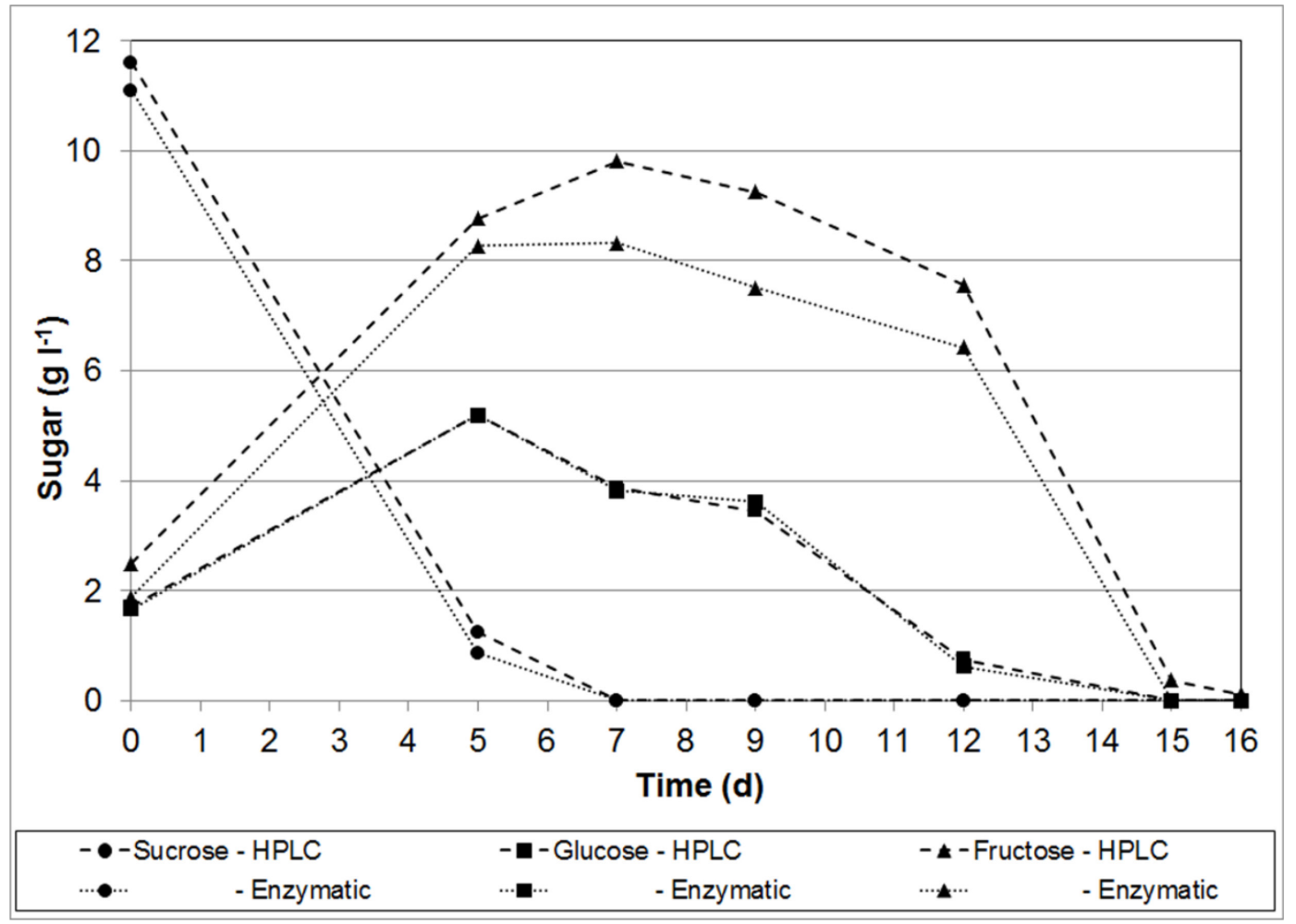

Fig. 7 Extracellular sugar concentrations in MS1 with about $15 \mathrm{~g} \mathrm{l}^{-1}$ initial sucrose content while a $\mathrm{HA}_{\mathrm{pm} 15}$ culture grows at $26^{\circ} \mathrm{C}$ and $125 \mu \mathrm{mol} \mathrm{m} \mathrm{m}^{-2} \mathrm{~s}^{-1}$. (•) Sucrose, (घ) glucose, $(\boldsymbol{\Delta})$ fructose. Comparison of HPLC (dashed lines) with enzymatic analysis (dotted lines)

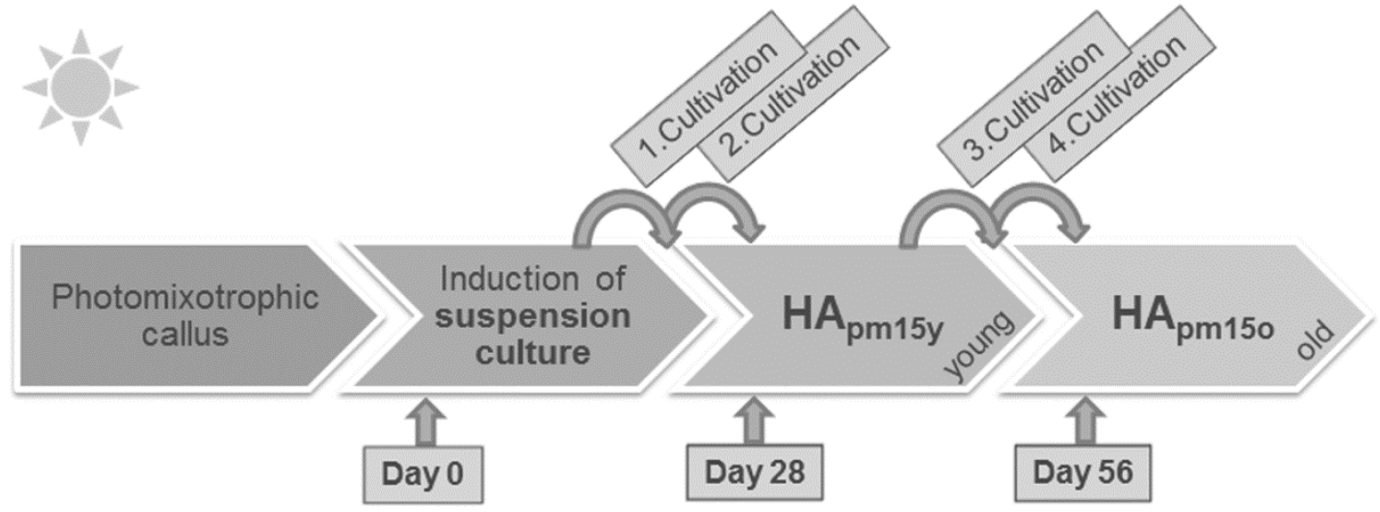

Fig. 8 Visualization of culture age and sub-culture cycles of $\mathrm{HA}_{\mathrm{pm} 15}$ culture 


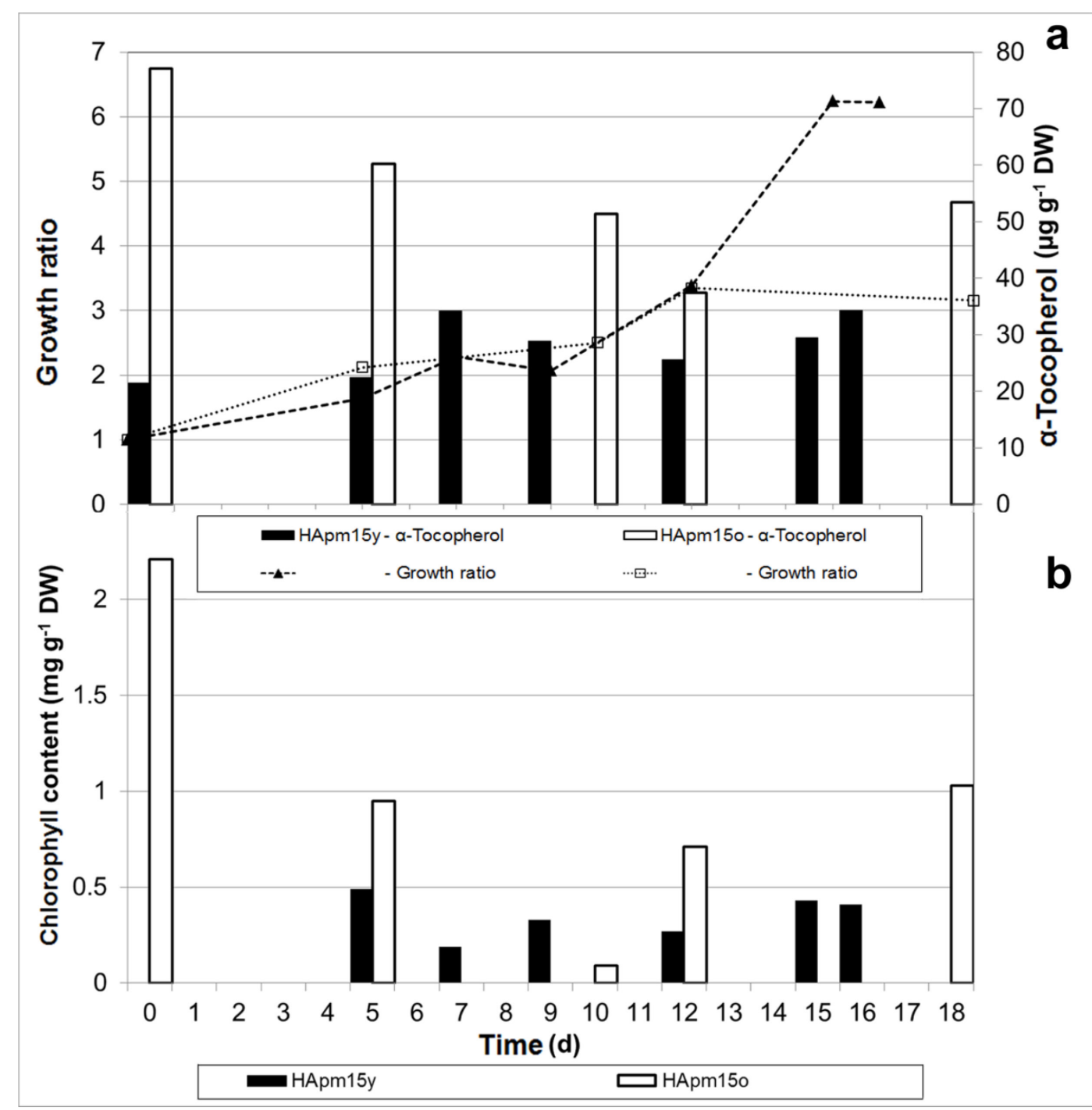

Fig. 9 Effect of culture age on growth, $\alpha$-tocopherol and chlorophyll synthesis. a Growth ratios of $\mathrm{HA}_{\mathrm{pm} 15 \mathrm{y}}$ (4 weeks after induction; dashed line) and $\mathrm{HA}_{\mathrm{pm} 15 \mathrm{o}}$ (8 weeks after induction; dotted line) culture. $\alpha$-Tocopherol content in $\mathrm{HA}_{\mathrm{pm} 15 \mathrm{y}}$ (black column) and $\mathrm{HA}_{\mathrm{pm} 15 \mathrm{o}}$ (white column) culture. b Chlorophyll content in $\mathrm{HA}_{\mathrm{pm} 15 \mathrm{y}}$ (black column) and $\mathrm{HA}_{\mathrm{pm} 15 \mathrm{o}}$ (white column) culture 